\title{
A PROTEÇÃO IMPERATIVA DOS DIREITOS LABORAIS DE MIGRANTES INDOCUMENTADOS
}

Karlin Olbertz ${ }^{1}$

\section{RESUMO}

A situação vulnerável dos migrantes indocumentados obriga muitas vezes que aceitem quaisquer condições de trabalho. Temem a delação às autoridades mas precisam de sustento, o que faz com que trabalhem sob exploração, sem qualquer garantia de seus direitos. $O$ desenvolvimento do Direito Internacional possibilitou que tais direitos fossem declarados imperativos, em função da elevação do princípio da igualdade e não discriminação à categoria de jus cogens.

\section{ABSTRACT}

The vulnerable situation of undocumented immigrants compels them to accept, in many times, any work conditions. Even tough they fear the called from authorities, they need sustenance, which forces them to work under exploration, without any guarantee of their rights. The development of the International Law made possible for those rights to be declarated imperatives, because of the rise from equality and no discrimination principle to jus cogens category.

Palavras-chave: Direito Internacional, trabalhador migrante, jus cogens.

Keywords: International Law, immigrant worker, jus cogens.

\footnotetext{
${ }^{1}$ Acadêmica de Direito da Universidade Federal do Paraná e Pesquisadora do Núcleo de Estudos em Direito Internacional da Universidade Federal do Paraná.
}

Revista Brasileira de Direito Internacional, Curitiba, v.5, n.5, jan./jun.2007 


\section{FENÔMENO DA MIGRAÇÃO IRREGULAR}

Sofrendo golpes brutais do desemprego, da miséria, da guerra, de perseguições, milhões de pessoas emigram, buscando em outros países uma forma de sobreviverem. Famílias inteiras deslocam-se na esperança de melhores condições, ou de apenas continuarem existindo. Sabe-se que muitos destes migrantes são indocumentados, o que significa dizer que se encontram em situação irregular nos países para os quais se dirigiram. São os "imigrantes ilegais", representando para alguns perigo tão grande que capaz de provocar a construção de um muro, protejendo um gigante (em dimensão e riquezas, digase, exatamente o que se dá com os Estados Unidos da América), mas que, em verdade e por outro lado, temem (os imigrantes) pela manutenção de suas vidas.

Nos termos da Convenção Internacional sobre a Proteção de Direitos de Todos os Trabalhadores Migratórios e de seus Familiares, migrante indocumentado é aquele que não foi autorizado a ingressar, permanecer e exercer atividade remunerada no Estado de emprego, de acordo com as leis internas desse Estado ou com os tratados dos quais seja parte, mas que ainda assim o faz. O fenômeno dessa migração é planetário e em muito devido à escassez de emprego, principalmente nos países ainda em desenvolvimento.

Se a busca é por melhores condições, necessário trabalhar, com o intuito de obter renda que possibilite a subsistência. Mas a condição de migrante irregular é complicadora para se conseguir um emprego; e aqui, quando se fala em emprego, quer se dizer um trabalho que assegure sustento adequado, descanso, e no mais, os direitos inerentes à relação de emprego. Ao migrante indocumentado restam muitas vezes os subempregos, os "bicos", os trabalhos em condições insalubres ou perigosas. Sua posição é de flagrante vulnerabilidade, pois para não ser delatado às autoridades, acaba obrigado a aceitar o que the oferecem, ainda que em prejuízo de sua dignidade. $\mathrm{Na}$ realidade, toda a família migrante irregular sofre com este status, pois enfrenta dificuldades no acesso à saúde pública, à educação gratuita para os fihos, à 
moradia, na profissão de sua cultura e crenças, e para piorar, torna-se alvo de preconceitos.

A fim de que não seja delatado às autoridades migratórias, nem pereça na miséria, o migrante irregular pode ter de se submeter a explorações e chantagens na relação de trabalho, sem contar a exclusão social que enfrenta, até porque a própria condição de migrante, mesmo que regular, já é fator de não aceitação. Basta recordar os movimentos xenofóbicos, tão conhecidos. Nesse sentido, o migrante cede a tudo, com vistas à sua integridade e a de sua família, e não tem seus direitos mais fundamentais respeitados e garantidos.

Revista Brasileira de Direito Internacional, Curitiba, v.5, n.5, jan.jun.2007 


\section{PROBLEMA DA GLOBALIZAÇÃO}

No mundo da Idade Industrial, sabíamos quem desfrutava do lucro, como nos recorda FORRESTER. Havia disparidade de posições, mas todos pertenciam a um mesmo sistema. Este mundo em que os locais de trabalho e de economia se fundiam deu lugar a outro, o da globalização, das transnacionais, do liberalismo, da virtualidade, da flexibilização do trabalho, e de uma grande leva de desempregados, seres humanos em excesso, não condizentes com a lógica do lucro - mas, diga-se, cuja miséria pode ser aproveitada por ela.

É no sentido oferecido por CHESNAIS que a globalização mostra sua natureza bifronte: benéfica e necessária ao progresso tecnológico e à ampliação do mercado, mas prejudicial ao contingente de trabalhadores, pois geradora de uma massa de desempregados, propriciando a utilização da mãode-obra mais barata dos países periféricos. A queda das fronteiras financeiras representa a estes países o desnudamento para mostra de suas fragilidades, e é assim que a mundialização do capital traz à tona a mundialização da questão social. Ainda com CHESNAIS, poucos países em desenvolvimento conseguiram manter alguma competição no mercado, e atualmente

(...) muitos países, certas regiões dentro de países, e até áreas continentais inteiras (na África, na Ásia e mesmo na América Latina) não são mais alcançados pelo movimento de mundialização do capital, a não ser sob a forma contraditória de sua própria marginalização (...), mecanismo complementar e análogo ao da exclusão da esfera de atividade produtiva, que atinge, dentro de cada país, uma parte da população, tanto nos países industrializados como nos países em desenvolvimento. ${ }^{2}$ (grifo nosso).

As conquistas do direito do trabalho estão entre aquelas ameaçadas pelo processo de globalização. A investida é apoiada por instituições como o Banco Mundial e o Fundo Monetário Internacional, na medida em que defendem a flexibilização. FORRESTER nos traz provas da existência deste empreendimento:

\footnotetext{
${ }^{2}$ CHESNAIS, François. A mundialização do capital. São Paulo: Xamã, 1996, p. 18.
}

Revista Brasileira de Direito Internacional, Curitiba, v.5, n.5, jan./jun.2007 
É necessário, em todos os países, encurtar a duração dos direitos quando for muito longa ou tornar as condições de admissão mais restritas. (...). Uma flexibilidade aumentada do mercado de trabalho (...) é essencial para todas as regiões que empreendem reformas em profundidade. ${ }^{3}$ (Publicação do Banco Mundial, "World Department Report, Workers in an Integrating World", Oxford University Press, 1995).

Os governos europeus não devem deixar que os temores suscitados pelas consequiências de sua ação sobre a distribuição de renda os impeçam de lançar-se com audácia numa reforma profunda dos mercados de trabalho. A flexibilização destes últimos passa pela mudança do seguro-desemprego, do salário mínimo legal e das disposições que protegem o emprego. ${ }^{4}$ (Boletim do FMI, de 23 de maio de 1994).

Destarte, o estímulo ao trabalho está no auge em lugares onde a miséria e a ausência de qualquer proteção social diminuem o custo da mão-deobra a quase nada. Muitas empresas estrangeiras instalam-se nestes locais, esquecendo-se de que são forças de uma nação, provocando mudanças prejudiciais, desempregando em massa, empobrecendo toda uma região. Ressalta FORRESTER que as fugas de capitais, por sua vez, privam de recursos as estruturas econômicas e sociais do Estado caloteado. E com isso a opinião pública não se preocupa - tem por bode expiatório os estrangeiros que vêm supostamente roubar seus empregos (inexistentes) e esvaziar a previdência social. Para a autora, não deveríamos esquecer que estes mesmos imigrados vão para países que um dia também já foram suas pátrias; “...emigram para o país daqueles (então indignados) que intervieram, na África, por exemplo, como visitantes bem mais interessados que nossos imigrados".

É a situação enfrentada pelos migrantes, e mais especialmente, os irregulares. Decorre de fatores como a transferência de empresas para regiões com mão-de-obra mais barata, diante do que o país de origem, numa tentativa de atrair outros mercados, também vem fixar salários mais baixos. Neste contexto, sem contar aquelas situações de conflito, guerra, etc., os trabalhadores migram, buscando Estados com mais proteção e melhor

\footnotetext{
${ }^{3}$ DECORNOY, 1995, citado por FORRESTER, Viviane. O horror econômico. Tradução de Álvaro Lorencini. São Paulo: Editora da Universidade Estadual Paulista, 1997, p. 92.

${ }^{4}$ DECORNOY, 1995, citado por FORRESTER, Viviane. O horror econômico. Tradução de Álvaro Lorencini. São Paulo: Editora da Universidade Estadual Paulista 1997, p. 93.

${ }^{5}$ FORRESTER, Viviane. O horror econômico. Tradução de Álvaro Lorencini. São Paulo: Editora da Universidade Estadual Paulista, 1997, p. 100.
}

Revista Brasileira de Direito Internacional, Curitiba, v.5, n.5, jan./jun.2007 
remuneração - mas acabam por formar muitas vezes uma massa de excluídos, de desempregados.

SINGER também fornece dados à compreensão do problema. Para ele, a globalização causa o chamado "desemprego estrutural", que "não aumenta necessariamente o número total de pessoas sem trabalho, mas contribui para deteriorar o mercado de trabalho para quem precisa vender sua capacidade de produzir" 6 . Entende que o desemprego é "a ponta de um iceberg muito maior, qual seja, a deteriorização das relações de trabalho"'7.

\footnotetext{
${ }^{6}$ SINGER, Paul. Globalização e desemprego: diagnóstico e alternativas. 4a ed. São Paulo: Contexto, 2001, p. 23.

${ }^{7}$ SINGER, Paul. Globalização e desemprego: diagnóstico e alternativas. 4ª ed. São Paulo: Contexto 2001, p. 7.
}

Revista Brasileira de Direito Internacional, Curitiba, v.5, n.5, jan./jun.2007 


\section{A INERÊNCIA DOS DIREITOS LABORAIS À PESSOA DO} TRABALHADOR

Assim como os direitos humanos, que surgem da própria condição de pessoa humana, os direitos laborais necessariamente são oriundos da condição do trabalhador, da relação de trabalho, e toda pessoa que realize uma atividade remunerada nos moldes da relação de trabalho adquire imediatamente essa condição.

É por isso que se diz que os direitos laborais existem como característica essencial à pessoa do trabalhador. Basta que este exerça atividade laborativa, com subordinação, e todos os direitos advindos da legislação trabalhista, inclusive a internacional vigente, são-lhe conferidos.

O migrante indocumentado (e qualquer pessoa) ao ser contratado para trabalhar torna-se titular dos direitos laborais inerentes a sua situação, sem que haja relação com seu status migratório. Este, muito embora irregular, não atinge o reconhecimento dos direitos laborais, pois não altera a condição do migrante como trabalhador.

A importância do trabalho para a economia de mercado - e do não trabalho, pois o exército de reserva é fator de aumento da mais-valia associada à acumulação e transação de bens, veio por reificar severamente o labor humano, com o que se dissociaram a figura do sujeito, trabalhador, e do resultado de seu trabalho. Ocorre que tal perspectiva não leva em conta que "o trabalho concebido como uma projeção indissociável da personalidade do trabalhador se identifica com as condições existenciais necessárias ao desenvolvimento físico, psíquico e social do sujeito" ${ }^{8}$. Assim é que trabalhador e trabalho são figuras indissociáveis, tal como vida privada e pessoa humana, e que a manutenção da vida do trabalhador é intríseca ao seu trabalho, circunstância que se mostra relevante para a defesa dos direitos laborais fundamentais.

\footnotetext{
8 GEDIEL, José Antônio Peres. A irrenunciabilidade a direitos da personalidade pelo trabalhador. In SARLET, Ingo Wolfgang (org.). Constituição, Direitos Fundamentais e Direito Privado. $2^{\mathrm{a}}$ edição, revista e ampliada. Porto Alegre: Livraria do Advogado, 2006, p. 153.
}

Revista Brasileira de Direito Internacional, Curitiba, v.5, n.5, jan./jun.2007 
COUTINHO assevera que nunca na história foi tão grande o número de militantes do exército de reserva desejando a própria exploração. Entretanto, destaca que

de modo inafastável nas relações de emprego sempre estará uma "pessoa humana", impregnada e carregada de direitos fundamentais que desvelam e afloram sua dignidade; daí porquanto a objetivação do trabalho, em parte, oculta o sujeito titular de direitos que deve ser (re)focado. ${ }^{9}$

O migrante indocumentado deixa seu país em busca de meios para continuar vivendo. Tem a esperança de encontrar, para si e sua família, uma ocupação que Ihe possibilite o sustento, e é um daqueles militantes capazes de desejar a própria exploração, se o motivo for a subsistência. Envergonhado de sua condição - e como nos lembra FORRESTER, a vergonha deveria ter cotação na bolsa, pois incrementa o lucro - submete-se aos desatinos de um capitalismo sem limites. Termina por se encontrar num país onde não pode existir, vez que ilegal, e precisa trabalhar. É o fim de sua subjetividade, "e não há pior horror que o fim de si próprio quando ocorre bem antes da morte e se deve arrastar enquanto vivo" ${ }^{\prime 10}$.

Não se quer aqui rotular o mercado como o mal que aflige 0 trabalhador. O que se pretende é a constatação de que o trabalhador, qualquer que seja sua situação, é sujeito de direitos que devem ser garantidos e respeitados, e não mais um número na lógica do lucro. Neste sentido, aduz GEDIEL que

a atividade econômica, como expressão e exercício da livre iniciativa, da propriedade privada e da livre disposição dos bens individualmente apropriados, só se torna possível ao se apresentar conformada pelo respeito à dignidade humana e pelos direitos fundamentais. ${ }^{11}$

\footnotetext{
9 COUTINHO, Aldacy Rachid. A autonomia privada: em busca da defesa dos direitos fundamentais dos trabalhadores. In SARLET, Ingo Wolfgang (org.). Constituição, Direitos Fundamentais e Direito Privado. $2^{\mathrm{a}}$ edição, revista e ampliada. Porto Alegre: Livraria do Advogado, 2006, p. 182.

${ }^{10}$ FORRESTER, Viviane. O horror econômico. Tradução de Álvaro Lorencini. São Paulo: Editora da Universidade Estadual Paulista, 1997, p. 37.

${ }_{11}$ GEDIEL, in SARLET, Ingo Wolfgang (org.). Constituição, Direitos Fundamentais e Direito Privado. 2a edição, revista e ampliada. Porto Alegre: Livraria do Advogado, 2006, p. 158.
}

Revista Brasileira de Direito Internacional, Curitiba, v.5, n.5, jan./jun.2007 
Foi o reconhecimento dos direitos laborais como inerentes por igual a todos os trabalhadores que permitiu o desenvolvimento da jurisprudência internacional no sentido da proteção imperativa dos migrantes indocumentados. 


\section{O PROTESTO MEXICANO}

Para a situação dos migrantes indocumentados atentou o Estado do México quando, em 10 de maio de 2002, solicitou à Corte Interamericana de Direitos Humanos uma opinião consultiva. Seu processo e conclusão se intenta relatar, ressaltando-se a importância do direito à igualdade perante a lei e à não discriminação, inerente à pessoa humana, previsto em diversos instrumentos internacionais. O parecer da Corte é paradigmático no que concerne à proteção imperativa dos direitos laborais.

Com fundamento no artigo 64.1 da Convenção Americana sobre Direitos Humanos, o Estado do México solicitou a referida opinião consultiva, argüindo acerca da

(...) privação de gozo e exercício de certos direitos laborais (aos trabalhadores migrantes) e sua compatibilidade com a obrigação dos Estados americanos de garantir os princípios de igualdade jurídica, não discriminação e proteção igualitária e efetiva da lei consagrados em instrumentos internacionais de proteção aos direitos humanos, assim com a subordinação ou condicionamento da observância das obrigações impostas pelo direito internacional dos direitos humanos, incluídas aquelas oponíveis erga omnes, frente à consecução de certos objetivos de política interna de um Estado americano. $^{12}$

Assim, ao Governo do México preocupa muito a diferença de interpretações e práticas no que tange aos direitos humanos nos países da Organização dos Estados Americanos (OEA). Tudo isto diz respeito a uma situação bastante particular ao México: o grande número de migrantes mexicanos irregulares nos Estados Unidos da América, país que tem certas posições incompatíveis, adiante-se, com a garantia de direitos laborais aos trabalhadores migrantes indocumentados.

$\mathrm{Na}$ consulta, o Estado solicitante arrolou diversas normas de direito internacional cuja interpretação é requerida à Corte. Com base nelas, elaborou questões, buscando um parecer da Corte em tela.

\footnotetext{
${ }^{12}$ Corte I.D.H., Condición Jurídica Y Derechos de los Migrantes Indocumentados. Opinión Consultiva OC-18/03 de 17 de septiembre de 2003. Serie A, № 18. San Jose, C.R.: Corte I.D.H., 2004, p. 4. Tradução nossa.
}

Revista Brasileira de Direito Internacional, Curitiba, v.5, n.5, jan./jun.2007 
Sucintamente, deve-se dizer que entende o Governo do México haver a violação de certos direitos laborais, em virtude de critérios discriminatórios relativos à condição indocumentada de certos migrantes. Assim, não é assegurado o direito a licença maternidade, ao pagamento de horas extras, de salários vencidos, por exemplo, num evidente abuso da situação vulnerável destes trabalhadores.

\subsection{PROCEDIMENTO PERANTE A CORTE E CONTRIBUIÇÕES}

A consulta em questão recebeu diversas colaborações através de escritos apresentados por países e por amici curiae, tanto organizações como particulares. Destaque-se que em 13 de janeiro de 2003 o Estado dos Estados Unidos da América encaminhou nota à Corte informando que não apresentaria observações à solicitação. Audiências públicas foram convocadas para sustentações orais das observações apresentadas.

O Estado do México, ora solicitante, argumentou que há a possibilidade de os Estados tratarem de forma diferente os migrantes em situação irregular, desde que não tomem qualquer medida discriminatória no que diz respeito ao gozo e à proteção dos direitos humanos reconhecidos pela comunidade internacional. E há direitos que, se violados, redundam na violação também de direitos fundamentais, sendo essenciais à incolumidade dos princípios da igualdade perante a lei e da não discriminação, como o direito a igual salário por igual trabalho, a constituição de sindicatos, como a proibição do trabalho escravo e infantil. É neste sentido, defende o solicitante, que os Estados têm a obrigação erga omnes de respeitar o ser humano em sua dignidade, e o principal atributo desta é a igualdade de direitos.

A Comissão Interamericana de Direitos Humanos levantou critérios para que seja possível aos Estados adotarem medidas que limitem alguns direitos. Para tanto, deve-se levar em consideração que certos direitos são inderrogáveis, que há direitos exclusivos dos cidadãos, que há direitos condicionados ao status de migrante em situação regular, e que somente certos direitos podem ser restringidos; a restrição, por sua vez, deve estar 
prevista em lei, responder a interesse legítimo e explícito do Estado, relacionarse racionalmente com objetivo legítimo e deve ser a maneira menos onerosa para os afetados. A Comissão ainda defendeu que alguns direitos laborais são fundamentais.

Observaram os representantes da Universidade de São Francisco de Quito que os Estados têm a obrigação de suprimir leis que discriminem o gozo de direitos humanos, pois inadmissíveis, e mais, que todos os Estados (independente de serem signatários de convenção, pois obrigação de caráter erga omnes) têm o dever de impedir qualquer discriminação, mesmo que advinda de política migratória. Valeram-se do argumento de que há limites impostos ao poder dos Estados, determinados pelo costume internacional e pelas normas imperativas de direito internacional (jus cogens). Fazendo referência à importante noção de jus cogens, prevista no artigo 53 da Convenção de Viena sobre o Direito dos Tratados, de 1969, a Comissão explica que "o jus cogens incorpora valores fundamentais tão importantes que se impõem acima do consentimento dos Estados" ${ }^{\prime 3}$, condicionando a validez das normas. A dita Convenção determina requisitos para que uma norma seja caracterizada como de jus cogens, quais sejam: 1) status de norma de direito internacional geral; 2) aceitação pela comunidade internacional; 3) imunidade de derrogação; 4) modificável unicamente por uma norma do mesmo status. A Comissão termina por dizer que é imperativo que a Corte analise se o princípio de não discriminação e o direito à proteção igualitária e efetiva da lei podem ser tidos por normas de jus cogens.

A Delgado Law Firm trouxe à discussão o caso Hoffman Plastic Compounds Inc. v. National Labor Relations Board. Em decisão, a Suprema Corte dos Estados Unidos determinou que um empregador estadunidense pudesse violar os direitos laborais de um trabalhador migrante em situação irregular. Impôs uma multa ao empregador e não ordenou indenização nem compensação alguma em favor do trabalhador; isto porque, de acordo com os argumentos da Suprema Corte, o trabalhador teria incorrido em má conduta

\footnotetext{
${ }^{13}$ Corte I.D.H., Condición Jurídica Y Derechos de los Migrantes Indocumentados. Opinión Consultiva OC-18/03 de 17 de septiembre de 2003. Serie A, № 18. San Jose, C.R.: Corte I.D.H., 2004, p. 58/59. Tradução nossa.
}

Revista Brasileira de Direito Internacional, Curitiba, v.5, n.5, jan./jun.2007 
grave, justamente pelo fato trabalhar sendo indocumentado. Portanto, a Suprema Corte não negou que a despedida se deu em violação das leis laborais (o motivo para a despedida foi 0 fato de 0 trabalhador estar organizando um sindicato). O que fez foi tratar de forma desigual, se em comparação com um trabalhador nacional ou migrante legal, a pretensão daquele trabalhador. Defenderam os Estados Unidos da América que possuem política interna voltada ao desalento da imigração irregular, mas pelo que se percebe do julgamento do caso, tomam medidas que fazem da mão-de-obra do migrante indocumentado um atrativo aos empregadores. Ressalta a Delgado Law Firm, com razão, que "contar com mão de obra barata sem garantir os direitos humanos básicos não é uma política imigratória legítima" ${ }^{14}$, e que os Estados Unidos da América só têm benefícios com a mão-de-obra de três milhões de migrantes indocumentados vindos do México trabalhando no país.

Do Washington College of Law e do Programa de Direitos Humanos da Universidade Iberoamericana do México se tem o argumento de que "é do mais elementar sentido de justiça que se garanta que uma pessoa que tenha trabalhado receba seus benefícios salariais" ${ }^{\prime 15}$, sendo que, do contrário, se estaria dando legitimidade ao trabalho escravo.

A última colaboração aqui recordada é a do Conselho Centroamericano de Procuradores de Direitos Humanos. Com sua observação, trazem à nota mais uma vez a questão do jus cogens. Assim, a obrigação de respeitar e garantir os direitos humanos não vem de outro lugar senão da própria natureza dos direitos humanos e da dignidade do ser humano, que por transcendência são jus cogens. $\mathrm{E}$ o princípio de não discriminação e $\mathrm{O}$ direito a proteção igualitária e efetiva da lei devem ser considerados normas de jus cogens.

E é exatamente na noção de jus cogens que se pretende aqui calcar o fundamento da necessária proteção dos direitos dos migrantes indocumentados, como fez a Corte.

\footnotetext{
${ }^{14}$ Corte I.D.H., Condición Jurídica Y Derechos de los Migrantes Indocumentados. Opinión Consultiva OC-18/03 de 17 de septiembre de 2003. Serie A, № 18. San Jose, C.R.: Corte I.D.H., 2004, p. 63. Tradução nossa.

${ }_{15}$ Corte I.D.H., Condición Jurídica Y Derechos de los Migrantes Indocumentados. Opinión Consultiva OC-18/03 de 17 de septiembre de 2003. Serie A, № 18. San Jose, C.R.: Corte I.D.H., 2004, p. 103. Tradução nossa.
}

Revista Brasileira de Direito Internacional, Curitiba, v.5, n.5, jan./jun.2007 


\section{CONSIDERAÇÕES DA CORTE INTERAMERICANA DE DIREITOS HUMANOS}

Sempre vale recordar que os direitos humanos devem ser respeitados e garantidos por todos os Estados, obrigação geral que encontra lugar em diversos instrumentos internacionais. A Corte Interamericana de Direitos Humanos entende ser a igualdade um atributo inerente à pessoa humana, que acompanha sua dignidade, possuindo caráter fundamental na defesa dos direitos humanos.

Tanto assim que pode um Estado, segundo a Corte, tratar distintamente duas situações; quando se fala em distinção, quer-se dizer que a atuação do Estado é aceitável, pois razoável, proporcional e objetiva. Pode, entretanto, ocorrer que um Estado exceda seus limites e aponte para o inaceitável, violando os direitos humanos; aí se está diante de discriminação, extrapolando-se a proporção entre os meios e o que se quer alcançar.

O Comitê de Direitos Humanos das Nações Unidas, ao definir discriminação, refere-se a toda distinção que se baseie em motivos como raça, religião, opinião, dentre outros, com vistas a depreciar o reconhecimento, gozo e exercício dos direitos e liberdades fundamentais em condições igualitárias. Não significa o dever de tratar todos de maneira igual em todas as circunstâncias, pois a igualdade muitas vezes deve ser promovida. Ocorre que é conforme o princípio da igualdade e da não discriminação que deve atuar o Estado, no sentido de respeitar e garantir os direitos humanos, sob pena de responsabilidade internacional.

Pelo caráter fundamental do princípio da igualdade e não discriminação, inadmitindo-se ato jurídico que com ele entre em conflito, defende a Corte ser o mesmo pertencente à categoria de norma imperativa de direito internacional, ou jus cogens. É a obrigação geral, de caráter erga omnes, imposta a todos Estados, e em função da configuração do princípio da igualdade e da não discriminação como jus cogens, exige-se atuação positiva, a fim de que se respeite e efetivamente se garanta a observância do princípio.

Revista Brasileira de Direito Internacional, Curitiba, v.5, n.5, jan./jun.2007 
Destarte, aos Estados é permitido somente estabelecerem distinções objetivas e razoáveis, atentando para a salvaguarda dos direitos humanos e de acordo com o princípio da aplicação da norma que melhor proteja o ser humano. Ainda, deve o Estado assegurar que toda pessoa tenha de fato acesso a recursos que patrocinem seus direitos. É de se reparar que os termos aqui utilizados são "pessoa", "ser humano"; não se faz, portanto, menção ao status migratório, pois o princípio deve ser observado pelo simples fato de se tratar de um ser humano. E, ressalte-se, o descumprimento das obrigações erga omnes trazidas pelo jus cogens gera responsabilidade internacional do Estado.

O entendimento final da Corte vai ao encontro do exposto até agora. Conclui que as distinções entre pessoas são possíveis, desde que obedecidos os requisitos da razoabilidade, objetividade e proporcionalidade, e não se aflijam direitos humanos. Que a situação regular de uma pessoa num Estado não é exigência para que tal Estado a respeite em seus valores fundamentais, dos quais emerge o princípio da igualdade e da não discriminação, a ser sobremaneira garantido. Assim é que um migrante indocumentado não pode ser constrangido na sua esfera de direitos laborais, isto pelo simples motivo de serem tais direitos inerentes à condição de trabalhador.

A corte admite que os direitos dos migrantes não têm sido reconhecidos em todas as partes do mundo. Sua vulnerabilidade é flagrante, sendo empregados geralmente em condições adversas, diferentes das que se aplicam aos trabalhadores nacionais. Os custos com o emprego de um trabalhador migrante indocumentado podem ser extremamente reduzidos, pois como já observado, sua situação irregular atemoriza e faz com que aceitem pactuar uma relação de trabalho sem as devidas garantias. Mas o problema não se reduz a essa constatação: as empresas que contratam migrantes indocumentados, além de fazerem proveito do lucro advindo da mão-de-obra do migrante, são protagonistas de uma concorrência desleal para com as empresas que não tomam partido.

No que concerne às obrigações do Estado, compreende a Corte que ele deve agir nos sentido de prevenir, investigar e sancionar as violações aos 
direitos humanos. Também que a obrigação de respeito e garantia dos direitos humanos tem efeitos nas relações individuais e, portanto, todas as pessoas devem respeitar tais direitos, incluindo o empregador no que tange aos seus trabalhadores. Neste caso o Estado também é responsável ao se comportar de forma a tolerar, aquiescer ou negligenciar a conduta de violação aos direitos humanos.

Vale dizer que a Corte, referindo-se a direitos laborais, considera serem aqueles reconhecidos ao trabalhador pelo sistema jurídico nacional e internacional. E inúmeros são os instrumentos internacionais que trazem orientação quanto aos direitos laborais, cuja interpretação deve sempre se dar de acordo com o princípio da norma que melhor proteja a pessoa humana - no caso, o trabalhador.

O exercício dos direitos laborais fundamentais permite que 0 trabalhador e sua família desfrutem de uma vida com dignidade. A proibição do trabalho forçado, do trabalho infantil, os direitos da mulher trabalhadora, 0 direito à liberdade de associação, a salário justo, seguridade social, duração de jornada, descanso e indenização, são direitos de titularidade de todos os trabalhadores, qualquer que seja sua situação migratória.

Do exposto, deduz a Corte que os migrantes indocumentados "(...)possuem os mesmos direitos laborais que correspondem aos demais trabalhadores do Estado de emprego", e o dito Estado "deve tomar as medidas necessárias para que assim se reconheça e se cumpra na prática"16. Deste modo, a observância do princípio da igualdade perante a lei e não discriminação é incondicional, não subordinado às políticas de cada Estado, inclusive as de caráter migratório.

Por unanimidade, opinou a Corte, em síntese, que o princípio da igualdade e da não discriminação é norma imperativa de direito internacional público (jus cogens) e

que a qualidade migratória de uma pessoa não pode constituir uma justificação para privá-la do gozo e exercício de seus direitos humanos, entre

\footnotetext{
${ }^{16}$ Corte I.D.H., Condición Jurídica Y Derechos de los Migrantes Indocumentados. Opinión Consultiva OC-18/03 de 17 de septiembre de 2003. Serie A, № 18. San Jose, C.R.: Corte I.D.H., 2004, p. 204. Tradução nossa.
}

Revista Brasileira de Direito Internacional, Curitiba, v.5, n.5, jan./jun.2007 
eles os de caráter laboral. O migrante, ao assumir uma relação de trabalho, adquire direitos por ser trabalhador, que devem ser reconhecidos e garantidos, independentemente de sua situação regular ou irregular no Estado de emprego. ${ }^{17}$

17 Corte I.D.H., Condición Jurídica Y Derechos de los Migrantes Indocumentados. Opinión Consultiva OC-18/03 de 17 de septiembre de 2003. Serie A, № 18. San Jose, C.R.: Corte I.D.H., 2004, p. 210. Tradução nossa.

Revista Brasileira de Direito Internacional, Curitiba, v.5, n.5, jan./jun.2007 


\section{JUS COGENS: INSTRUMENTO DETERMINANTE DA PROTEÇÃO INTERNACIONAL IMPERATIVA DO TRABALHADOR MIGRANTE}

Expresso na Convenção de Viena sobre Direito dos Tratados, artigo 53 , donde pela primeira vez surgiu numa normativa internacional, o termo jus cogens refere-se às normas de cunho imperativo e cuja observação não pode ser afastada.

Causa estranheza falar-se em norma imperativa, haja vista que "todas as normas jurídicas são obrigatórias, a priori ${ }^{18}$. Ocorre que 0 respeito às normas de jus cogens significa mais que uma obrigatoriedade; isto porque 0 ato que Ihes seja contrário é tido por nulo, conforme prescreve o próprio artigo 53, da dita Convenção: é nulo o tratado que, no momento de sua conclusão, conflita com uma norma imperativa de direito internacional geral. É neste sentido que se diz que as normas imperativas de direito internacional não admitem qualquer limitação. Se determinada questão eleva-se à categoria de jus cogens, como espécie de jus cogens superveniente, as cláusulas dos tratados anteriores que conflitarem com o novo entendimento sofrerão também a nulidade.

São princípios de jus cogens, por exemplo, o da autodeterminação dos povos e o do non-refoulement (direito de um migrante não retornar ao país de origem no caso, por exemplo, de perseguição ou catástrofe). Pelo jus cogens estão proibidos o genocídio, a escravidão, a tortura, o apartheid, a contaminação do meio ambiente, a violação dos direitos humanos. E nessa nova estrutura do direito internacional, tais normas não podem ser afastadas ou modificadas, senão por normas de direito internacional da mesma natureza.

Assinala FRIEDRICH que a elevação dos direitos humanos à categoria de jus cogens

(...) está condicionada a duas mudanças estruturais do cenário internacional: o reconhecimento do indivíduo como sujeito de direito internacional e de sua

\footnotetext{
${ }^{18}$ FRIEDRICH, Tatyana Scheila. As Normas Imperativas de Direito Internacional Público - Jus Cogens. Belo Horizonte: Editora Fórum, 2004, p. 32.
}

Revista Brasileira de Direito Internacional, Curitiba, v.5, n.5, jan./jun.2007 
capacidade jurídica para interpor, perante as cortes nacionais ou internacionais, ação relacionada à violação de direito internacional. ${ }^{19}$

De fato ao longo dos anos o direito internacional, preponderantemente voluntarista, vem assumindo colorações de humanização, inadmitindo vontades estatais que não condigam com o respeito ao ser humano. "Acima da vontade está a consciência" ${ }^{20}$, nos recorda CANÇADO TRINDADE, em seu voto na Opinião Consultiva abordada. Para que esse respeito seja comum, o jus cogens apresenta uma característica bastante interessante: é gerador de obrigações erga omnes. Isto devido à flagrante importância de suas normas, no juízo de que a todos os Estados da comunidade internacional é importante sua proteção. Destarte, todos os países obrigam-se para com o não descumprimento de normativas de jus cogens, signatários ou não das convenções que the afirmem.

CANÇADO TRINDADE observa o despertar de uma consciência jurídica universal, cuja manifestação inequívoca é o reconhecimento de normas de direito internacional com caráter de jus cogens. Lembra que ninguém hoje negaria as invocações da Cláusula Martens ${ }^{21}$ acerca das leis e da consciência da humanidade como pertencentes ao jus cogens, podendo ser considerada como limitação às razões de Estado, por razões de toda a humanidade.

Quase ao término de seu voto, CANÇADO TRINDADE fala dos princípios gerais de direito reconhecidos como fundamentais, sendo evidente que tais princípios não dependem do consentimento ou da vontade dos sujeitos de Direito e, no âmbito do direito internacional, dos Estados. Coloca nesta posição o princípio da dignidade do ser humano e da inalienabilidade dos direitos inerentes à pessoa, valores que se identificam com o jus cogens. Para o jurista, aplica-se o mesmo pensamento ao princípio da igualdade e da não discriminação, consagrado em diversas normativas internacionais de direitos

\footnotetext{
${ }^{19}$ FRIEDRICH, Tatyana Scheila. As Normas Imperativas de Direito Internacional Público - Jus Cogens. Belo Horizonte: Editora Fórum, 2004, p. 106.

${ }^{20}$ Corte I.D.H., Condición Jurídica Y Derechos de los Migrantes Indocumentados. Opinión Consultiva OC-18/03 de 17 de septiembre de 2003. Serie A, № 18. San Jose, C.R.: Corte I.D.H., 2004, p. 266. Tradução nossa.

21 "Os habitantes e beligerantes permanecem sob a proteção e a regulamentação dos princípios do direito das nações, uma vez que estes resultam dos usos estabelecidos entre povos civilizados, das leis da humanidade e dos ditames da consciência pública". Convenção de Haia de 1907.
}

Revista Brasileira de Direito Internacional, Curitiba, v.5, n.5, jan./jun.2007 
humanos, de suma importância para a proteção dos migrantes indocumentados. Ressalta que a atual doutrina é pacífica quanto à consideração do dito princípio como um dos pilares do Direito Internacional dos Direitos Humanos, ocupando, ainda, posição central no documento das Nações Unidas de 1998 contendo Princípios Básicos sobre Deslocamento Interno, cuja idéia é a de que os migrantes não perdem seus direitos humanos e os inerentes à condição humana em razão do deslocamento, sob quaisquer condições.

Em tempo, o jus cogens não se limita ao direito dos tratados, mas é próprio também do direito da responsabilidade internacional dos Estados. $E$ para CANÇADO TRINDADE, é neste ponto que o jus cogens assume sua real amplitude, ao alcançar todos os atos jurídicos que lhe sejam contrários.

Não há dúvida de que o trabalho escravo, por exemplo, afronta a consciência jurídica universal, como expressão da comunidade internacional como um todo. Sua proibição, neste sentido, é norma de jus cogens, assim como o direito ao devido processo legal e o princípio da igualdade perante a lei e não discriminação, todos significativos à proteção dos direitos laborais dos migrantes indocumentados.

CANÇADO TRINDADE aponta duas dimensões para as obrigações erga omnes, advindas do jus cogens: uma horizontal, que diz respeito à proteção dos seres humanos pela comunidade internacional como um todo (erga omnes partes); e uma vertical, que vincula o poder público e os indivíduos.

Resta que todos os Estados, independente de convenção, e todos os indivíduos, como sujeitos de direito internacional, têm o dever de respeito e garantia aos direitos humanos; para tanto, devem agir de forma positiva, no sentido de não permitir a violação de tais direitos, e particularmente do direito à igualdade e não discriminação, a fim de que outros direitos inerentes à pessoa humana - e portanto, de toda pessoa humana, regular ou não sua situação de permanência em um país como migrante - possam ser exercidos, tais como os laborais, em sua plenitude.

Revista Brasileira de Direito Internacional, Curitiba, v.5, n.5, jan./jun.2007 


\section{CONVENÇÕES E DECLARAÇÕES}

Diversos instrumentos internacionais tratam da proteção aos trabalhadores. Foram eleitos para ilustração alguns dos mais abrangentes, visando aclarar 0 tratamento que $o$ direito internacional oferece a estas pessoas.

\subsection{A CONVENÇÃO INTERNACIONAL SOBRE A PROTEÇÃO DO TRABALHADOR MIGRANTE}

Em 18 de dezembro de 1990 a Assembléia Geral das Nações Unidas aprovou a Convenção Internacional sobre a Proteção dos Direitos de Todos os Trabalhadores Migrantes e seus Familiares, estabelecendo normas fundamentais para proteção dos trabalhadores migrantes, muito em função da discriminação que sofrem. É a primeira convenção a tratar do assunto de forma mais particularizada.

Há referência no preâmbulo da preocupação de vários órgãos internacionais, principalmente no que concerne à migração irregular, a qual mais deixa de receber proteção adequada. No preâmbulo também se reconhece a vulnerabilidade dos trabalhadores migrantes, quer regulares ou irregulares, por serem empregados em condições menos favoráveis que os trabalhadores nacionais, o que beneficia a obtenção de lucro pelas empresas.

O artigo $1^{\circ}$ da Convenção destaca que a mesma é aplicada a todos os trabalhadores migrantes e seus familiares, sem distinção. Vivifica-se com isso o princípio da igualdade e da não discriminação, que elevado à categoria de jus cogens, tornou-se cerne da proteção.

A Parte III faz referência aos direitos humanos dos trabalhadores migrantes e seus familiares, arrolando muitos artigos e reconhecendo direitos e proibições, tais como a da escravidão ou do trabalho forçado. À luz dos artigos 25 e 26, os trabalhadores migrantes têm os mesmos direitos dos nacionais no que diz respeito à relação de trabalho e à atividade sindical.

Revista Brasileira de Direito Internacional, Curitiba, v.5, n.5, jan./jun.2007 
Outros direitos são atribuídos aos trabalhadores migrantes documentados, pelo artigo 36 da Convenção, como o da liberdade de movimento e residência e acesso à educação.

O artigo 69 conclama à colaboração para que se regule a situação dos trabalhadores migrantes indocumentados, prevendo o artigo 70 a adoção de medidas internas para igualdade de tratamento frente aos trabalhadores nacionais.

Ao final, a Parte VII prevê a criação de um Comitê de Proteção aos Direitos de Todos os Trabalhadores Migrantes e Seus Familiares, cujo papel é examinar relatórios dos Estados partes e receber comunicações de tais Estados e de particulares.

\subsection{A CARTA INTERNACIONAL AMERICANA DE GARANTIAS} SOCIAIS

Os Estados americanos adotaram na IX Conferência Internacional Americana, em Bogotá, no ano de 1948, a Carta Internacional Americana de Garantias Sociais.

Pelo artigo primeiro, compromete-se a carta a declarar os princípios fundamentais de amparo aos trabalhadores de toda classe, identificando um mínimo de direitos dos quais devem os trabalhadores gozar nos Estados Americanos. Os princípios básicos são destacados pelo artigo $2^{\circ}$. A alínea $b$ deste artigo preceitua que todo trabalhador deve ter a possibilidade de uma existência digna e condições adequadas de trabalho. Pela alínea $d$, por igual trabalho deve haver igual remuneração.

O direito à liberdade de associação vem abarcado pelo artigo 26 da Carta, que também faz referência à proteção devida às associações.

\subsection{CARTA SOCIAL EUROPÉIA}

Assinada em 18 de outubro de 1961, em Turin, a Carta Social Européia reiteradamente reconhece direitos a todos os trabalhadores. Neste sentido, 
afirma que todos os trabalhadores têm direito a condições de trabalho justas, a remuneração justa, a associarem-se livremente, a negociar coletivamente.

Peca a Carta Social Européia em seu artigo 19, partes 4 e 7, quando se refere aos trabalhadores migrantes e suas famílias. Há restrição de direitos, garantindo-se tratamento não menos favorável que aos nacionais apenas para os trabalhadores que se encontrem legalmente no território do Estado empregador. Esse trato igualitário abrange: a) remuneração e condições de trabalho; b) liberdade de associação; c) ações judiciais que tenham por fundamento $o$ artigo.

Ora, a violação do direito a tratamento igualitário, como visto, deve gerar responsabilidade internacional, em virtude do princípio da igualdade e não discriminação estar abrangido pelo âmbito do jus cogens. Ainda, a convenção que conter cláusula desconforme com o jus cogens, deve ser considerada nula. É de se ousar dizer que as disposições citadas violam inclusive direitos inerentes à pessoa humana, como o de condições adequadas de trabalho.

7.4 PACTO INTERNACIONAL DE DIREITOS ECONÔMICOS, SOCIAIS E CULTURAIS E PACTO INTERNACIONAL DE DIREITOS CIVIS E POLÍTICOS

Adotados em dezembro de 1966, em vigor desde 1976. Pelo primeiro, as partes signatárias reconhecem direitos, dentre eles alguns específicos do trabalhador. $\mathrm{O}$ artigo $7^{\circ}$ proclama o direito a condições de trabalho justas; 0 artigo $8^{\circ}$, à formação de sindicatos.

O grande valor está prescrito no artigo $2^{\circ}$, parte 1 , do Pacto Internacional de Direitos Civis e Políticos. Por ele, os Estados signatários comprometem-se a respeitar e garantir a todos os indivíduos que se encontrem em seus territórios e sujeitos a suas jurisdições os direitos constantes do pacto, sem discriminação alguma por qualquer condição. Emerge mais uma vez o fundamental princípio da igualdade perante a lei e da não discriminação. $O$ mesmo artigo ainda prevê que os Estados partes devem tomar providências

Revista Brasileira de Direito Internacional, Curitiba, v.5, n.5, jan./jun.2007 
para efetivar os direitos reconhecidos, em atuações positivas, garantindo a toda pessoa cujos direitos tenham sido violados o acesso a um recurso, e efetivo, 0 que vem a fortificar o direito ao devido processo legal.

As disposições referidas do Pacto Internacional de Direitos Civil e Políticos foram de suma importância para o reconhecimento dos princípios da igualdade e não discriminação e do devido processo legal como normas imperativas de direito internacional.

Revista Brasileira de Direito Internacional, Curitiba, v.5, n.5, jan./jun.2007 


\section{A NECESSÁRIA SOLIDARIEDADE}

Diante de tão grave realidade, como é a dos migrantes indocumentados, resta a atuação decidida da comunidade internacional, no sentido de possibilitar que estas pessoas não se tornem protagonistas da perpetuação da miséria, alvos da marginalização e do sentimento xenofóbico; pelo contrário, deve-se garantir que suas vidas correspondam ao existir digno da pessoa humana.

CANÇADO TRINDADE considera importante para a análise do caso a renitência da disparidade entre as nações, trazida pela globalização, as migrações forçadas e a situação vulnerável dos migrantes. Em suas palavras, o drama desses migrantes "(...)só poderá ser eficazmente tratado em meio a um espírito de verdadeira solidariedade humana para com os vitimizados", e apenas "a firme determinação de reconstrução da comunidade internacional sobre a base da solidariedade humana poderá levar à superação de todos estes traumas"22. Vem acrescentar que

\footnotetext{
em tempos da assim chamada 'globalização' (o neologismo dissimulado e falso que está na moda em nossos dias), as fronteiras se têm aberto aos capitais, bens e serviços, mas se têm tristemente fechado aos seres humanos. ${ }^{23}$ (grifo nosso).
}

O apelo aqui é para que a atenção dos Estados se volte ao ser humano, numa tentativa de recolocar a pessoa no centro do ordenamento jurídico, em especial o internacional, na busca da humanização e solidarização do direito das gentes. A compreensão que se deve arraigar é a de que a solidariedade entre os países - e por que não, entre as pessoas, sujeitos de direito internacional cada vez mais ativos - seja capaz de solucionar questões como a dos migrantes indocumentados, associada ao respeito efetivo às

\footnotetext{
${ }^{22}$ Corte I.D.H., Condición Jurídica Y Derechos de los Migrantes Indocumentados. Opinión Consultiva OC-18/03 de 17 de septiembre de 2003. Serie A, № 18. San Jose, C.R.: Corte I.D.H., 2004, p. 222. Tradução nossa.

${ }^{23}$ Corte I.D.H., Condición Jurídica Y Derechos de los Migrantes Indocumentados. Opinión Consultiva OC-18/03 de 17 de septiembre de 2003. Serie A, № 18. San Jose, C.R.: Corte I.D.H., 2004, p. 222. Tradução nossa.
}

Revista Brasileira de Direito Internacional, Curitiba, v.5, n.5, jan./jun.2007 
convenções e à jurisprudência internacional, principalmente pelos países desenvolvidos.

Que a elevação dos direitos laborais dos trabalhadores migrantes indocumentados à categoria de direitos imperativos na ordem internacional possibilite que estas pessoas não sejam tratadas como um problema do qual o país receptor simplesmente precisa se desfazer, mediante deportação. Nem que sejam explorados como mão-de-obra barata pelas empresas, aptas a intensificar o lucro, mas em detrimento da condição humana. Espera-se que este seja o desenvolver da declarada categoria de proteção.

E se tudo isto for considerado utópico, inalcansável, impossível diante da globalização, da lógica do lucro desenfreado e do capitalismo ilimitado, que seja lembrado mais uma vez CANÇADO TRINDADE, ao alertar os descrentes e descompromissados que "a alternativa à utopia é a desesperação" ${ }^{24}$.

${ }^{24}$ Corte I.D.H., Condición Jurídica Y Derechos de los Migrantes Indocumentados. Opinión Consultiva OC-18/03 de 17 de septiembre de 2003. Serie A, № 18. San Jose, C.R.: Corte I.D.H., 2004, p. 236. Tradução nossa.

Revista Brasileira de Direito Internacional, Curitiba, v.5, n.5, jan./jun.2007 


\section{REFERÊNCIAS}

Condición jurídica y derechos de los migrantes indocumentados, Opinión Consultiva OC-18/03 de 17 de septiembre de 2003. Corte Interamericana de Derechos Humanos, San José, C.R.: Corte IDH, 2004.

CHESNAIS, François. A mundialização do capital. São Paulo: Xamã, 1996.

COUTINHO, Aldacy Rachid. A autonomia privada: em busca da defesa dos direitos fundamentais dos trabalhadores. In SARLET, Ingo Wolfgang (org.). Constituição, Direitos Fundamentais e Direito Privado. 2 $2^{\mathrm{a}}$ edição, revista e ampliada. Porto Alegre: Livraria do Advogado, 2006.

FORRESTER, Viviane. O Horror Econômico, tradução de Álvaro Lorencini. São Paulo: Editora da Universidade Estadual Paulista, 1997.

FRIEDRICH, Tatyana Scheila. As Normas Imperativas de Direito Internacional Público - Jus Cogens. Belo Horizonte: Editora Fórum, 2004.

GEDIEL, José Antônio Peres. A irrenunciabilidade a direitos da personalidade pelo trabalhador. In SARLET, Ingo Wolfgang (org.). Constituição, Direitos Fundamentais e Direito Privado. $2^{\mathrm{a}}$ edição, revista e ampliada. Porto Alegre: Livraria do Advogado, 2006.

SINGER, Paul. Globalização e desemprego: diagnóstico e alternativas. $4^{\text {a }}$ ed. São Paulo: Contexto, 2001. 